\title{
BUKU BERGAMBAR SEBAGAI MEDIA PEMBELAJARAN KISAH SAHABAT NABI DENGAN PEMANFAATAN AUGMENTED REALITY
}

\author{
${ }^{1)}$ Rhoma Doni , 2) Pratama Benny Herlandy, ${ }^{3)}$ Harun Mukhtar \\ ${ }^{1,3)}$ Teknik Informatika Universitas Muhammadiyah Riau \\ ${ }^{2)}$ Pendidikan Informatika Universitas Muhammadiyah Riau \\ ${ }^{1,2,3)} \mathrm{Jl}$. KH. Ahmad Dahlan No. 88, Sukajadi, Kota Pekanbaru \\ E-mail:rhomadoni@student.umri.ac.id,pratamabenny@umri.ac.id,harunmukhtar@umri.ac.id
}

\begin{abstract}
ABSTRAK
Pada awal tahun 2014, sebuah survey penggunaan smartphone dan tablet oleh anak-anak telah dilakukan oleh theAsianParent Insight bersama Samsung Kidstime di Asia Tenggara. Sebanyak 2.714 orang tua beserta 3.917 orang anak berusia 3-8 tahun telah menjadi responden survey ini. $85 \%$ orang tua mengharapkan anaknya untuk menggunakan smartphone untuk aplikasi pendidikan, namun $72 \%$ anak usia dini lebih memilih bermain game. Metode NFT merupakan penggabungan dari beberapa metode seperti SIFT dan Ferns yang terdapat pada SDK Vuforia SDK untuk mengembangkan aplikasi dengan teknologi augmented reality. Dengan menerapan teknologi augmented reality pada buku cerita bergambar ini, diharapkan buku dapat menigkatkan kualitas pendidikan. Dari hasil pengujian Black Box, aplikasi ARBook ini dapat menjalankan setiap fungsifungsinya dengan baik.
\end{abstract}

Kata Kunci : Pendidikan, Augmented Reality, NFT, SIFT, Ferns, Buku Cerita Bergambar

\section{ABSTRACT}

As early as 2014, a survey of smartphone and tablet use by children has been done by theAsianParent Insight with Samsung Kidstime in Southeast Asia. A total of 2,714 parents and 3,917 children aged 3-8 years have been the respondents of this survey. $85 \%$ of parents expect their children to use smartphones for educational apps, but $72 \%$ of younger children prefer to play games. The NFT method is an amalgamation of several methods such as SIFT and Ferns contained in the Vuforia SDK to develop applications with augmented reality technology. By applying augmented reality technology to this illustrated story book, it is hoped that the book can improve the quality of education. From the Black Box test results, this ARBook application can run every function properly.

Keywords: Education, Augmented Reality, NFT, SIFT, Ferns, Picture Book Stories

\section{PENDAHULUAN}

Semakin berkembangnya Smartphone ber-platfrom Android maka banyak masyarakat yang menggunakan bahkan anak-anak sudah mulai mengetahui cara penggunaan smartphone. Sejalan dengan perkembangan teknologi informasi, suatu inovasi baru sangat dibutuhkan dalam dunia pendidikan karena dengan adanya inovasi baru tersebut kualitas pendidikan dapat ditingkatkan.

Pada awal tahun 2014, sebuah survey penggunaan smartphone dan tablet oleh anak-anak telah dilakukan oleh theAsianParent Insight bersama Samsung Kidstime di Asia Tenggara. Hasilnya 98\% anak-anak di Asia Tenggara menggunakan Mobile Devices (theAsianparent Insights, 2014). Dari survey ini juga memperlihatkan bahwa $83 \%$ orang tua menginginkan anaknya menggunakan smartphone untuk aplikasi buku namun $72 \%$ anak - anaknya cenderung menggunakan smartphone untuk aplikasi game. 
Cerita bergambar sebagai media grafis yang dipergunakan dalam proses pembelajaran, memiliki pengertian praktis, yaitu dapat mengkomunikasikan fakta-fakta dan gagasan-gagasan secara jelas dan kuat melalui perpaduan antara pengungkapan kata-kata dan gambar [1].

Augmented reality (AR) merupakan teknologi yang mampu menggabungkan objek maya dua dimensi (2D) dan atau tiga dimensi (3D) ke dalam sebuah lingkungan nyata, kemudian memproyeksikan objekobjek tersebut secara real-time [2]. Pemanfaatan augmented reality dalam buku bercerita bergambar dimaksudkan untuk memperkaya pengalaman penggunanya, membantu presepsi dan interaksi penggunanya dengan dunia nyata. Informasi yang ditampilkan oleh benda maya dari buku bercerita bergambar diharapkan membantu pengguna melaksanakan kegiatan dunia nyata dalam hal mendidik, komunikasi, interaksi dan belajar.

Augmented reality (AR) merupakan teknologi yang mampu menggabungkan objek maya dua dimensi (2D) atau tiga dimensi (3D) ke dalam sebuah lingkungan nyata, kemudian memproyeksikan objekobjek tersebut secara real-time [2]. Augmented reality sebagai penggabungan benda-benda nyata dan maya di lingkungan nyata. Hasilnya ditampilkan secara interaktif dan dalam waktu nyata. Fungsi augmented reality adalah untuk menambahkan informasi dan makna pada sebuah objek nyata atau tempat. Dibutuhkan objek nyata atau ruang sebagai dasar dan menggabungkan teknologi yang menambahkan data kontekstual untuk memperdalam pemahaman seseorang dari subjek [3]. AR bukanlah sebuah aplikasi yang berdiri sendiri, AR menggunakan komputer, webcam, atau head-mounted display (HMD) atau perangkat lainnya untuk mendukung fungsinya [4].

Marker based tracking adalah augmented reality yang menggunakan marker atau penanda objek dua dimensi yang memiliki suatu pola yang akan dibaca komputer melalui media webcam atau kamera yang tersambung dengan komputer, biasanya merupakan ilustrasi hitam dan putih persegi dengan batas hitam tebal dan latar belakang putih [3].

Metode markerless dengan metode ini, pengguna tidak perlu lagi mencetak sebuah marker untuk menampilkan elemen-elemen digital. Dalam hal ini, marker yang dikenali berbentuk posisi perangkat arah, maupun lokasi [3]. Selain itu metode ini juga dapat menggunakan objek nyata 3D, smartterrain, image target, Multi image target, Virtual button dan motion gesture sebagai penandanya.

Media adalah sesuatu yang dapat digunakan untuk menyampaikan pesan dan dapat merangsang fikiran hingga perasaan sehingga dapat menimbulkan motivasi dan minat seseorang terhadap hal yang disampaikan. Media diartikan dalam fungsinya pada pembelajaran dapat diartikan sebagai berbagai jenis komponen dalam lingkungan siswa yang dapat merangsangnya untuk belajar [5]. Dalam perkembangannya hingga saat ini, media pembelajaran bergerak progresif kearah pengembangan media berbasis teknologi dan informasi. 
Keuntungan dari penggunaan media pembelajaran berbasis teknologi informasi adalah diantaranya sebagai bagian dari program pendidikan jarak jauh, dan untuk mengajak siswa memanfaatkan kebiasaan mereka dengan teknologi agar lebih dimanfaatkan dalam proses belajar mengajar. Melalui teknologi dan informasi maka media pembelajaran yang dihasilkan mampu untuk menghidupkan, mengkomunikasikan dan mentransfer informasi dengan lebih dinamis. Selain itu, juga dapat membantu siswa memvisualisasikan fenomena yang tidak dapat dilihat secara kasat mata atau telah terjadi dalam waktu yang lama [6]. Salah satu bentuk teknologi informasi yang dapat digunakan sebagai media pembelajaran oleh guru adalah pemanfaatan ponsel cerdas (smartphones).

Smartphone adalah perangkat teknologi yang hampir dimiliki oleh semua orang. Hasil pengamatan di lapangan, hampir setiap siswa SMA di Kota Pekanbaru memiliki smartphone. Berdasarkan data dari Telkomsel, bahwa pengguna Android mencapai \pm 2 juta orang. Berdasarkan pernyataan tersebut maka smartphone berbasis Android memiliki potensi yang bagus untuk dapat dimanfaatkan sebagai media penyampaian pembelajaran interaktif bagi siswa [7].

SIFT adalah singkatan dari Scale Invariant Feature Transform merupakan metode yang mengambil titik-titik fitur yang ada pada suatu citra, untuk membantu memastikan dalam pencocokan titik fitur suatu obyek pada sudut pandang yang berbeda [6]. Algoritma ini digunakan untuk untuk menyelesaikan masalah rotasi gambar, scaling, deformasi affine, perubahan sudut pandang, gangguan gambar, perubahan cahaya dan juga memiliki ketahanan yang kuat. Algoritma ini sangat baik dalam mengekstrak gambar namun membebani prosessor dalam hal komputasi.

Metode Ferns merupakan sebuah metode yang memanfaatkan kesesuaian titik kunci (keypoint) sebuah citra. Umumnya, metode ini digunakan untuk mendeteksi objek yang berupa bidang datar. Pada metode Ferns, mengidentifikasi petak tekstur yang dikelilingi oleh titik kunci pada citra diperoleh dari beragam bentuk dan kondisi pencahayaan. Hasil yang diperoleh dapat digunakan untuk mencatat perbedaan sudut pandang dari keadaan yang sama, mengekstraksi informasi objek 3D, atau mengikuti objek dalam video [8]. Ferns menggunakan klasifikasi fitur yang cepat, tetapi membutuhkan kapasitas memori yang besar.

Image ratings mendefinisikan seberapa baik gambar dapat dideteksi dan dilacak menggunakan SDK Vuforia. Rating berkisar dari $0-5$ bintang semakin baik gambar yang di unggah pada web portal Vuforia maka akan mendapatkan peringkat 1 sampai 5, sementara jika peringkat 0 maka gambar tersebut tidak dapat dikenali atau dideteksi oleh SDK Vuforia.

Vuforia merupakan SDK (software development kit) yang dikembangkan oleh Qualcomm untuk membantu pengembang dalam menciptakan aplikasi atau game yang memiliki teknologi augmented reality. Vuforia juga mendukung iOS, Android, serta Unity3D dan lain-lain sehingga 
memudahkan pengembang untuk membuat aplikasi yang dapat digunakan dihampir seluruh jenis smartphone dan tablet. Vuforia merupakan perangkat lunak yang dikembangkan oleh Qualcomm untuk mendukung dalam pembuatan Augmented Reality.

Vuforia menggunakan sumber yang berupa target konsisten mengenai computer vision yang fokus pada image recognition. Terdapat beberapa jenis target pada Vuforia, yaitu: 1) Image Target, misalnya: foto, halaman majalah, sampul buku, poster, kartu ucapan, 2) Frame Markers, tipe frame gambar dua dimensi dengan pola khusus yang dapat digunakan sebagai permainan, 3) Multi-target, contohnya kemasan produk atau produk yang berbentuk kotak maupun persegi, jenis ini dapat menampilkan gambar sederhana Augmented Reality dalam bentuk tiga dimensi, 4) Virtual Button, yang dapat membuat tombol sebagai daerah kotak sebagai sasaran gambar [9]. Untuk implementasi pengembangan dari Augmented Reality pada Vuforia, maka diperlukan perangkat aplikasi smartphone yang dapat dikembangkan dengan perangkat lunak Unity 3D.

Unity $3 \mathrm{D}$ adalah sebuah sebuah IDE yang terintegrasi untuk membuat game, arsitektur bangunan dan simulasi. Unity3D tidak hanya merupakan sebuah game engine, tapi juga merupakan sebuah editor. Kelebihan Unity3D yaitu multiplatform, platform yang didukung oleh Unity3D diantaranya adalah Windows, Mac, iPhone, iPad, Android,Xbox, PS3, WEB GL, SAMSUNG TV, Nintendo Wii, Flash, dan juga browser. Untuk browser, kita memerlukan sebuah plugin, yaitu Unity3D Web Player, sama halnya dengan Flash Player pada Browser. Bahasa pemrograman yang digunakan bermacam-macam, mulai dari Javascript, C\#, dan Boo. Unity3D juga memiliki asset store sehingga pengembang aplikasi dapat mengunduh objek, tampilan pengguna, script, plugin dan lain-lain untuk mendukung pengembangan aplikasi.

\section{METODE}

Masalah yang telah berhasil dianalisis pada latar belakang sebelumnya adalah bagaimana menerapkan teknologi augmented reality pada media buku cerita bergambar agar menjadi suatu inovasi dan meningkatkan kualitas pendidikan. Terdapat perbedaan signifikan terhadap perserta didik yang menggunakan media cerita bergambar dibandingkan dengan yang tidak menggunakan media cerita bergambar dalam hal menyimak dan membaca.

Dalam pengembangan media berbasis augmented reality, diperlukan beberapa spesifikasi perangkat minimum untuk menunjang kegiatan pengembangan. Spesifikasi minimum tersebut dikelompokkan berdasarkan kebutuhan perangkat keras dan lunak, serta kebutuhan minimum perangkat smartphone sebagai berikut.

Kebutuhan Perangkat Keras dan Lunak

Kebutuhan perangkat keras dalam pengembangan aplikasi ini sebagai berikut :

a. Processor Intel(R) Core(TM) i32370M CPU@2.40 GHz 2.40 $\mathrm{GHz}$.

b. VGA 2GB 
c. RAM 4GB

Kebutuhan perangkat lunak pengembangan aplikasi sebagai berikut :

a. Sistem operasi windows 8.1 (64bit)

b. IDE Unity 3D (64bit)

c. IDE desain Objek Blender (64bit)

d. Library marker SDK Vuforia 6.1.1.7

Kebutuhan minimum perangkat keras smartphone pengguna sebagai berikut :

a. CPU Quad Core $1 \mathrm{Ghz}$

b. RAM $1 \mathrm{~GB}$

c. Layar 4"

d. Kamera 2MP

e. Sistem Operasi Android Jelly Bea

\section{HASIL}

\section{Menu Utama}

Menu utama adalah halaman awal yang akan muncul ketika splash screen selesai ditampilkan. Halam ini memandu pengguna untuk memeilih beberapa fungsi. Tampilan menu utama terlihat pada gambar 4.1 berikut ini.

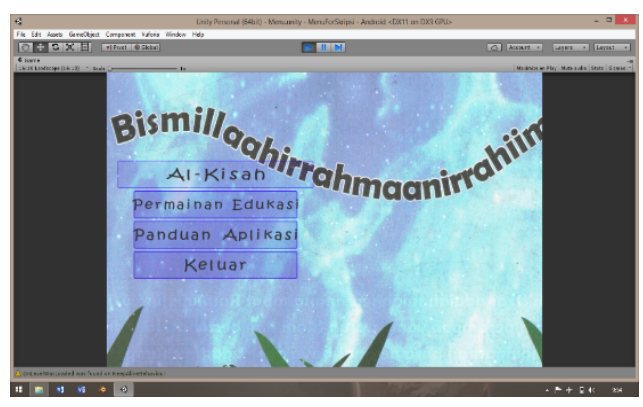

Gambar 1. Tampilan Menu Utama

Pada menu utama terdapat 3 fungsi utama yaitu pilihan cerita, panduan pengguna dan pilahn menutup aplikasi. Pada fungsi cerita augmented reality juga diterapkan fungsi posisition, scale, dan rotation objek serta penambahan narasi cerita.

\section{Tampilan Cerita}

Ketika pengguna memilih salah satu cerita, maka pengguna akan berpindah scene dari menu utama ke salah satu scene cerita. Antar muka cerita seperti terlihat pada gambar 3.2 dimana terdapat tombol panah arah kanan untuk berpindah adegan dan tombol panah kiri untuk kembali, terdapat tombol silang di atas kanan untuk kembali ke menu utama dan juga tombol gear untuk fungsi rotasi, scale, dan Posisiton.

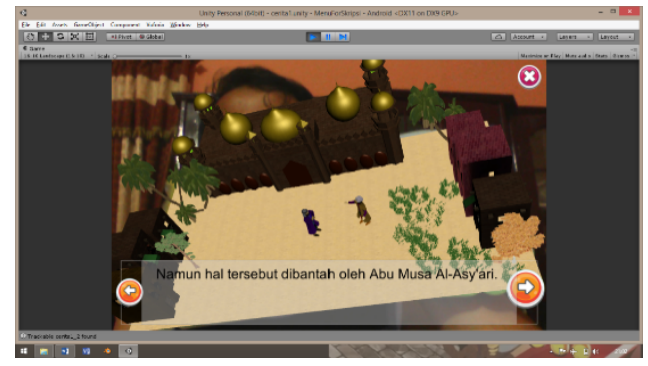

Gambar 2. Tampilan cerita

\section{Tampilan Panduan Aplikasi}

Tampilan panduan aplikasi berisi informasi cerita, panduan penggunaan aplikasi dan lain-lain. seperti terlihat pada gambar 3.3 berikut ini.

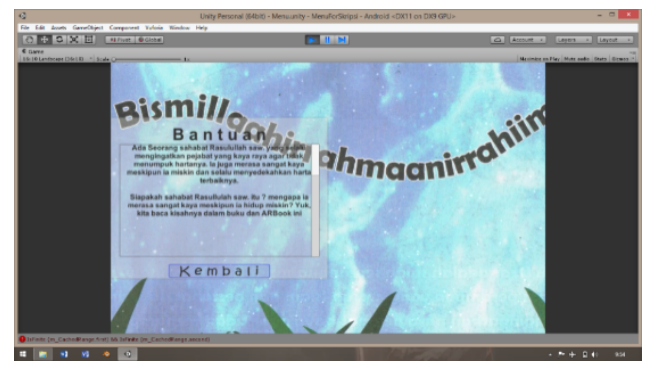

Gambar 3. Tampilan Panduan Aplikasi

\section{Tampilan Submenu Tutup Aplikasi}

Ketika pengguna memilih fungsi untuk menutup atau keluar aplikasi maka 
pengguna akan dihadapkan pada tampilan submenu konfirmasi keluar aplikasi seperti terlihat pada gambar 3.4 berikut ini.

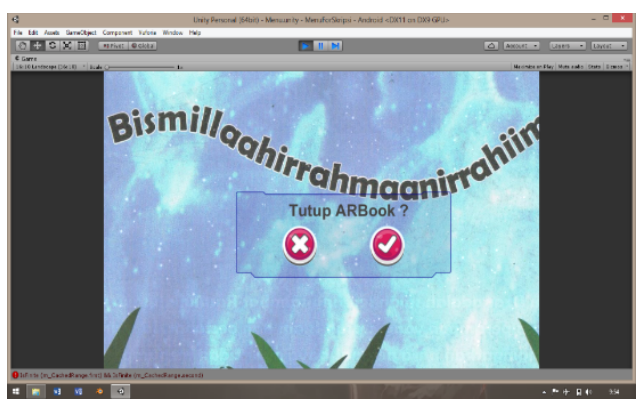

Gambar 4. Tampilan Submenu tutup aplikasi

\section{Pengujian}

Pengujian aplha dilakukan pada sisi pengembangan yang merekam semua kesalahan dan masalah saat pemakaian. Pengujian alpha dilakukan pada sebuah lingkungan yang terkendali. Pada pengujian yang telah dilakukan, didapatkan hasil bahwa sistem telah berjalan dengan baik. Namun hal ini tidak menutup kemungkinan akan terjadinya kesalahan pada sistem bahkan kesalahan pada pengguna.

\section{KESIMPULAN}

Penerapan teknologi augmented reality pada buku cerita bergambar sebagai media target berhasil diterapkan. Dengan penambahan objek 3 dimensi dan beberapa animasi pada objek tersebut sehingga objek 3 dimensi tersebut dapat menggabarkan cerita pada buku cerita bergambar tersebut. Hal ini juga menambah inovasi pada media buku yang sebelumnya hanya berupa teks dan gambar kini sudah berhasil diterapkan objek 3 dimensi dan animasi yang mengikuti alur dari cetita bergambar.
Dari hasil pengujian black box, aplikasi ARBook ini dapat menjalankan fungsifungsinya sesuai yang diharapkan. penerapan teknologi augmented reality pada buku cerita bergambar terdapat beberapa kekurangan seperti objek 3 dimensi yang hilang karena beberapa faktor, seperti pencahayaan, sudut kamera, dan kualitas gambar. Namun beberapa dapat ditangani dengan menggunakan aplikasi pada tempat yang memili cahaya yang cukup, jarak yang optimal $(30 \mathrm{~cm}$ sampai $80 \mathrm{~cm}$, serta sudut kamera yang optimal dengan media image target.

\section{DAFTAR PUSTAKA}

[1] Sudjana, Nana \& Riva'i, Ahmad. 2002. Media Pengajaran. Jakarta: Sinar Baru Algensindo.

[2] Yudiantika, A.R., Sulistiyo, S., \& Hantono, B.S. (2014). Evaluasi pelacakan tanpa marker pada metaio sdk untuk pengembangan aplikasi kuis berbasis augmented reality di museum. Seminar Nasional Teknologi Informasi dan Multimedia, 1(10), 07-12.

[3] Setyawan,R.A., \& Dzikri, A. 2016. Analisis penggunaan metode marker tracking pada augmented reality alat musik tradisional jawa tengah. Jurnal SIMETRIS, 07, 295-304.

[4] Abas, H. \& Zaman, H.B. (n.d.). Digital storytelling design with augmented reality technology for remedial students in learning bahasa melayu. Situs sumber http://s3.amazonaws.com/academia.e du.documents/45301347/Digital_Stor 
ytelling_Design_with_Augmented_R eality_Technology_for_Remedial_Stu dents_in_Learning_Bahasa_Melayu.p df [diakses pada 23/08/2016]

[5] Hiedayat, S. W. dan Sulistyowati. 2010. "Pengembangan Komputer Pembelajaran (CAI) tentang Gerak Lurus Berubah Beraturan pada Mata Pelajaran Fisika bagi Siswa Kelas VII SMP Negeri 2 Surabaya”. Jurnal Teknologi Pendidikan Universitas Negeri Surabaya 10 (1): 86-99.

[6] Rohmawati, L., Sucahyo, I., Arief, A., et al. (2015). Pelatihan penggunaan alat ukur dan pengukuran bagi guru IPA SMP Wilayah Sidoarjo. Jurnal ABDI, 1 (1), 18-24.

[7] Widaryani, R. (2012). Pelanggan telkomsel yang telah menggunakan ponsel pintar berjumlah 18 juta pelanggan dan dua juta di antaranya adalah pengguna ponsel pintar Android. Diambil pada tanggal 29 Juni 2015, dari http://tekno.kompas.com/read/2012/1 1/06/17141693

[8] Bimantoro, S. Imam, K. \& Sarwosri (n.d). Pembuatan alat kemudi dengan menggunakan open computer vision untuk spceship pd game orbiter spce flight simultor. Situs sumber : http://digilib.its.ac.id/public/ITSpaper-19731-5107100007-Paper.pdf

[9] Fernando Mario. 2013. Membuat Aplikasi Android Augmented Reality Menggunakan Vuforia SDK dan Unity. Solo. Buku AR Online. 